\title{
FeNi nanoparticles with carbon armor as sustainable hydrogenation catalysts: towards biorefineries $\dagger$
}

Cite this: J. Mater. Chem. A, 2014, 2, 11591

Received 15th May 2014

Accepted 28th May 2014

\author{
Gianpaolo Chieffi, Cristina Giordano, Markus Antonietti and Davide Esposito*
}

DOI: $10.1039 / c 4 t a 02457 e$

www.rsc.org/MaterialsA

Carbon supported FeNi nanoparticles were prepared by carbothermal reduction of cellulose filter paper impregnated with $\mathrm{Fe}$ and $\mathrm{Ni}$ salts. The resulting carbon enwrapped alloy nanoparticles were employed as an efficient catalyst for the continuous hydrogenation of molecules obtainable from different fractions of lignocellulosic biomass. Scaleup and time on stream tests over 80 hours proved the catalyst stable and durable of over a wide range of conditions.

\section{Introduction}

Catalytic hydrogenation has been one of the most studied reactions for decades. This versatile method for the reduction of an array of functional groups has found numerous applications and plays also a central role in the development of efficient biorefinery schemes for the production of hydrogen-rich fuels and chemicals from biomass. Catalytic hydrogenation is conveniently performed employing heterogeneous catalysts based on metals. ${ }^{1}$ Unfortunately, a considerable part of these metals belongs to groups 9 and 10 of the periodic table, resulting in a major drawback in terms of sustainability. ${ }^{2-5}$ Therefore, the scientific community accepted the challenge to replace scarce metals, especially those ones that are not mined but obtained exclusively as byproducts of major industrial metals, with other easily recoverable metals, including aluminum, iron, copper, nickel, tin and zinc.

Iron is one of the most abundant elements on Earth and the sixth most abundant elements in the Universe, ${ }^{6}$ and has been successfully used as a component of soluble ${ }^{7}$ or supported ${ }^{8,9}$ catalysts for specific hydrogenation reactions. Interestingly, the design of catalysts in which iron is alloyed with a second metal has resulted in increased activity and/or selectivity towards a given product ${ }^{10}$ due to the possible modulation of geometric

Max-Planck-Institute of Colloids and Interfaces, 14424 Potsdam, Germany. E-mail: davide.esposito@mpikg.mpg.de

$\dagger$ Electronic supplementary information (ESI) available. See DOI: $10.1039 / \mathrm{c} 4 \mathrm{ta} 02457 \mathrm{e}$ and electronic properties of the active sites. Moreover, catalyst stability is improved by inhibiting the sintering or the leaching of the active species through interaction with the second metal. The development of new sustainable hydrogenation catalysts with superior stability is also highly desired for the successful development of biorefineries for the conversion of raw lignocellulosic materials into chemicals and fuels, where poor selectivity and catalyst deactivation are sensibly affected by the high heterogeneity of biomass.

In the present work we describe the sustainable synthesis of a carbonized filter paper (CFP) supported bimetallic FeNi alloy catalyst and investigate its activity during the continuous hydrogenation of different functional groups and model biomass molecules. Nickel is also an abundant metal and showed remarkable catalytic activity for different applications. ${ }^{11,12}$ FeNi bimetallic alloys have been previously described and demonstrated improved catalytic performances with respect to pure Ni or Fe based catalysts. The group of Gallezot, for instance, observed that adding a second metal to 'RANEY®' $\mathrm{Ni}$ promoted the activation of $\mathrm{C}=\mathrm{O}$ bonds and increased the activity of the catalyst. ${ }^{13}$

More recently, Resasco et al. showed that the addition of Fe to $\mathrm{Ni} / \mathrm{SiO}_{2}$ shifted the product selectivity of the furfural reduction towards 2 -methylfuran, ${ }^{14}$ suppressing the competing decarbonylation.

The synthesis of such bimetallic alloys required often a number of sophisticated chemical and physical methods, including nonaqueous organometallic routes, ${ }^{15}$ ultrasonic spray pyrolysis ${ }^{16}$ or reducing agents as borohydrides that lead to FeNi nanoparticles (NPs) with boron inclusions. ${ }^{17}$ More recently incipient wetness and co-impregnation methods have been employed for this kind of synthesis. ${ }^{14}$ Here, a cheap and rapid approach for the synthesis of a supported catalyst has been designed, consisting in the impregnation of round lab-grade cellulose filter paper with the metal precursors of nickel $\left[\mathrm{Ni}\left(\mathrm{NO}_{3}\right)_{2} \cdot 6 \mathrm{H}_{2} \mathrm{O}\right]$ and iron $\left[\mathrm{Fe}\left(\mathrm{NO}_{3}\right)_{3} \cdot 9 \mathrm{H}_{2} \mathrm{O}\right]$ in optimizable mixing ratios. Afterwards, carbothermal reduction of iron and nickel salts has been performed leading to isolated NPs on the 
CFP support that preserve substantially the paper morphology at the microscale after thermal treatment. On the other side, the metals trigger the reorganization of the carbon matrix at the nanometer scale, resulting in the formation of a graphene-shell armor which encapsulate and stabilize the nanoparticles. ${ }^{\mathbf{1 8}}$ Reducing agents, multi-step and time consuming syntheses have been thereby completely avoided, affording a catalyst based entirely on sustainable precursors. The so-obtained supported NPs have been tested for hydrogenation in a fixedbed reactor, using water and ethanol as cheap and environmentally friendly solvents. We tested the properties of the readily obtained FeNi bimetallic catalysts for the hydrogenation of molecules that can be in principle derived from different fractions of the lignocellulosic feedstock, including glucose and levulinic acid from cellulose, xylose and furfural from hemicellulose.

Scale-up and time on stream experiments were performed to evaluate the stability and durability of the catalyst in view of possible application to large scale biorefinery processes.

\section{Catalyst characterization}

Cellulose filter paper was impregnated with an aqueous solution of the two metal precursors $\mathrm{Fe}$ and $\mathrm{Ni}(n \mathrm{Ni} / n \mathrm{Fe}=1.4)$ and then heat-treated at $800{ }^{\circ} \mathrm{C}$ for two hours under nitrogen flux to afford a dark, brittle and magnetic powder. Similar carbothermal reduction processes were previously employed by our group for the production of carbon-encapsulated iron carbide nanoparticles. ${ }^{18}$ The XRD pattern of the sample obtained is shown in Fig. 1.

The cubic crystalline FeNi phase is characterized by three distinctive diffraction peaks at $43.85^{\circ}, 50.10^{\circ}$ and $75.20^{\circ}$ (ICDD 04-002-8942). The peak at $26.10^{\circ}$ can be attributed to the (002) plane of hexagonal graphite. The crystalline size was calculated from the peak (111) using the Scherrer equation, which restituted the value of $20 \mathrm{~nm}$. Although XRD gives indicative information about the crystalline size of the nanoparticles, TEM and SEM were used to complement information on the size of the

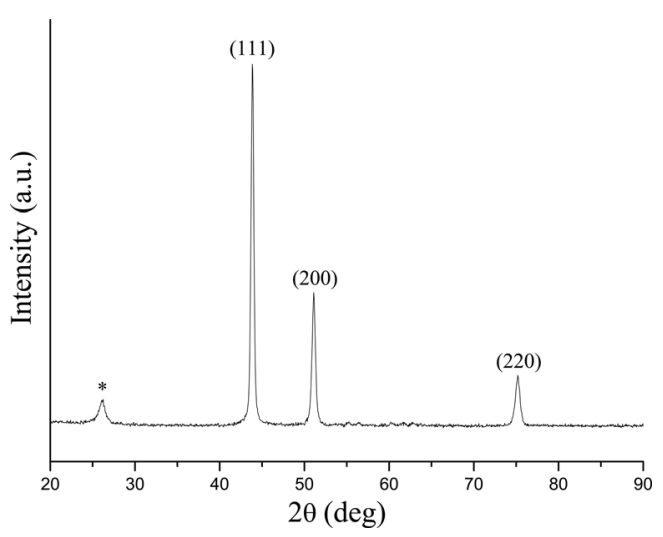

Fig. 1 XRD patterns of FeNi nanoparticles obtained via impregnation of lab grade cellulose filter paper with a solution of $\mathrm{Fe}\left(\mathrm{NO}_{3}\right)_{3} \cdot 9 \mathrm{H}_{2} \mathrm{O}$ and $\mathrm{Ni}\left(\mathrm{NO}_{3}\right)_{2} \cdot 6 \mathrm{H}_{2} \mathrm{O}$ and then heat-treated at $800{ }^{\circ} \mathrm{C}\left(10^{\circ} \mathrm{C} \mathrm{min}{ }^{-1}\right)$ for $2 \mathrm{~h}$ under nitrogen flux.

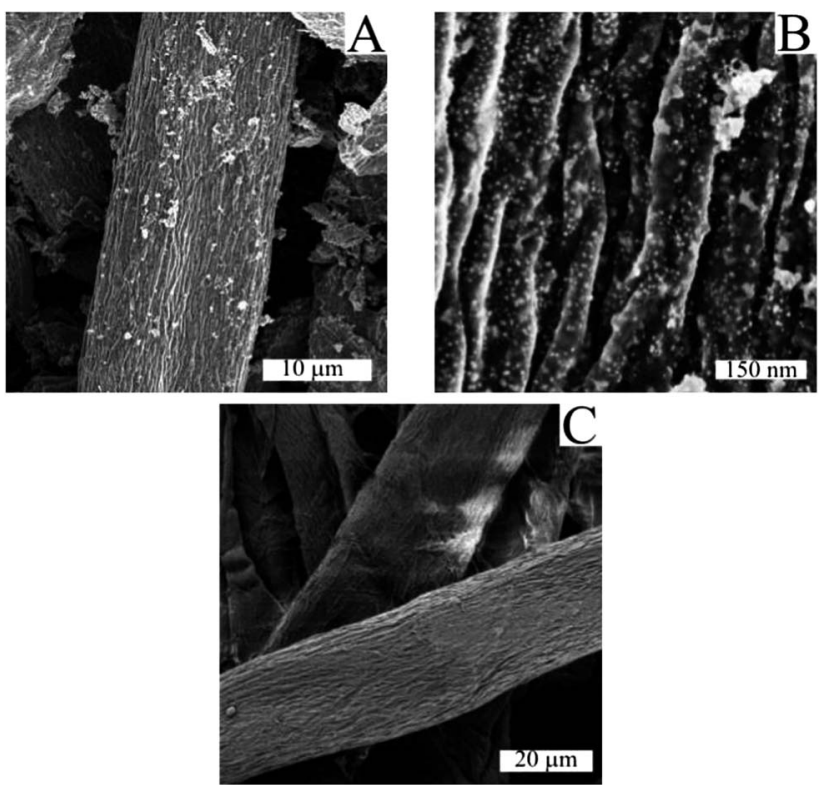

Fig. 2 (a) Low magnification and (b) high magnification SEM images of the cellulose filter paper impregnated with a solution of $\mathrm{Fe}\left(\mathrm{NO}_{3}\right)_{3} \cdot 9 \mathrm{H}_{2} \mathrm{O}$ and $\mathrm{Ni}\left(\mathrm{NO}_{3}\right)_{2} \cdot 6 \mathrm{H}_{2} \mathrm{O}$ and then heat-treated at $800{ }^{\circ} \mathrm{C}$ $\left(10{ }^{\circ} \mathrm{C} \mathrm{min}^{-1}\right)$ for $2 \mathrm{~h}$ under nitrogen flux. (c) Unannealed cellulose grade filter paper at room temperature.

particles, their morphology and surrounding. The SEM image in Fig. 2a shows the morphology of the CFP supported alloy nanoparticles. Although at the macroscopic level the high temperature treatment resulted in up to $60 \%$ shrinkage of the diameter of the cellulose filter paper, the spun cellulose superfibers as well as their primary fibril substructure are clearly visible and retained perfectly their shape and size when compared with the unannealed cellulose filter paper (see Fig. 2c).

A higher magnification (Fig. 2b) showed the carbon surface to be covered by bright spherical metal nanoparticles. The presence of iron and nickel on the carbon matrix was confirmed by EDX analysis (as shown in Fig. S1 $\dagger$ ), while the precise amount of carbon in the final hybrid was quantified to be around 44 $\mathrm{wt} \%$ by elemental analysis. The dimensional analysis exhibited
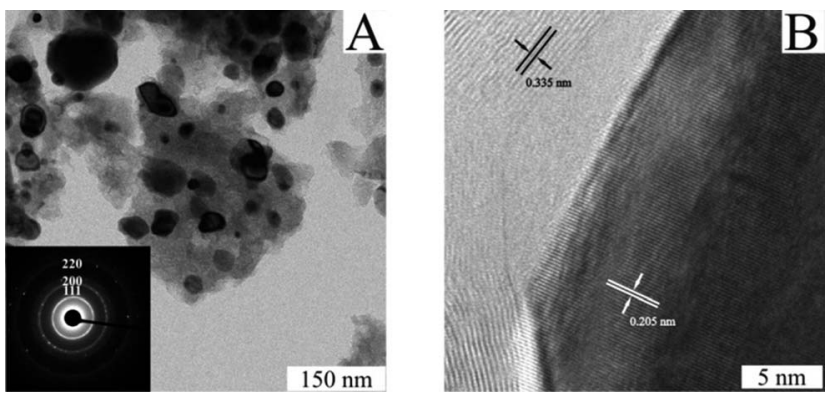

Fig. 3 Low magnification TEM image (a) and high-resolution TEM image with labeled lattice fringes (b) of CFP supported FeNi alloy nanoparticles. The SAED pattern reported in the inset of $(a)$ is indexed to the fcc lattice of FeNi alloy nanoparticles. 
a homogenous distribution of the size of the alloy nanoparticles centered at $31 \mathrm{~nm}$ (Fig. S2 $\dagger$ ).

The TEM bright field image in Fig. 3a revealed in the same way the presence of the alloy nanoparticles, seen here as dark entities on the surface of the carbonaceous matrix.

The size distribution of the nanoparticles with the maximum located at $26 \mathrm{~nm}$ is in agreement with the one calculated via SEM analysis (Fig. S3†). The SAED pattern recorded for these nanoparticles reveals the fcc crystalline structure (Fig. 3a inset). The lattice constant $a$ calculated from the (111) peak was $3.567 \AA$, resulted in a larger constant than that of fcc Ni $(a=$ $3.509 \AA$, ICDD 04-006-6387). These data proved the inclusion of $\mathrm{Fe}$ atom into the fcc Ni lattice resulted in an enlargement due to the greater radius of Fe. The HRTEM image of Fig. 3b taken from one of the nanoparticles showed a lattice fringe spacing of $0.205 \mathrm{~nm}$, corresponding well to the (111) planes of the fcc FeNi lattice. Well visible in the TEM image is also the occurrence of graphitic layers with a lattice fringe spacing of $0.335 \mathrm{~nm}$ relative to (002) planes of graphite, which enwrap and hold together the alloy NPs. The encapsulation of metal NPs in graphene layers has already shown to provide an effective mechanical reinforcement besides favoring stabilization. ${ }^{19}$ The fact that the particle size observed from both SEM and TEM images is slightly larger than the mean crystallite size calculated using the Scherrer equation from the XRD pattern $(20 \mathrm{~nm})$ suggest that these nanoparticles are partly conglomerates.

Brunnauer-Emmet-Teller (BET) analysis of the CFP supported alloy revealed a surface area of $88 \mathrm{~m}^{2} \mathrm{~g}^{-1}$, five times lower than the surface area of the CFP (Fig. S4 $\dagger$ ), as a result of the increased density of the hybrid nanocomposite.

\section{Catalytic tests}

The reactivity and the stability of the as synthesized material were tested to assess its potential as a catalyst for the hydrogenation of a range of functional groups characterized by different chemical reactivities and increasing bond energies $(E)$, i.e. $(\mathrm{C}=\mathrm{C}<\mathrm{C}=\mathrm{O}<\mathrm{C} \equiv \mathrm{C}<\mathrm{C} \equiv \mathrm{N}) .{ }^{20}$ The supported FeNi alloy powder was packed into a cartridge and directly employed as a catalyst into a bench-top continuous-flow reactor (H-Cube $\mathrm{Pro}^{\mathrm{TM}}$ ) provided with an internal hydrogen source and equipped with a liquid feed. Table 1 reports the conversions and selectivities for the hydrogenation of different substances.

The flow rate and hydrogen pressure were maintained generally constant at $1 \mathrm{~mL} \mathrm{~min}{ }^{-1}$ and $10 \mathrm{bar}_{2}$. Nevertheless, the employment of more severe conditions $\left(0.3 \mathrm{~mL} \mathrm{~min}^{-1}, 50\right.$ bar $\mathrm{H}_{2}$ ) was required due to the low reactivity of certain substrates towards reduction. The temperature, in turn, was optimized for each single molecule in order to achieve high conversions. Initially, we focused on the reduction of styrene and phenylacetylene into ethylbenzene which was quantitatively achieved at $50{ }^{\circ} \mathrm{C}$ using ethanol as the solvent (Table 1 , entries 1 and 2). The reduction of nitrobenzene to aniline, in contrast, required more energy and was complete at $100{ }^{\circ} \mathrm{C}$ with the same flow rate (entry 3 ).

In a similar way, the catalyst reduced the $\mathrm{C}=\mathrm{C}$ bond of 2cyclohexen-1-one $\left[E(\mathrm{C}=\mathrm{C}) \approx 148 \mathrm{kcal} \mathrm{mol}^{-1}\right.$ vs. $E(\mathrm{C}=\mathrm{O}) \approx 177$ kcal $\mathrm{mol}^{-1}$ ] (entry 4). The quantitative conversion of $\alpha$-terpinene, a conjugated diene isolated from marjoram and cardamom oils, required slightly higher temperatures and was achieved at $125{ }^{\circ} \mathrm{C}$ (entry 5) producing a mixture of two monoenes (56\% of 1-isopropyl-4-methylcyclohexene and $44 \%$ of 1methyl-4-isopropylcyclohexene). Similar results were obtained by Johnstone using an heterogeneous Pd catalyst, which showed that the $\alpha$-terpinene can form a ${ }^{4} \eta$ complex with the metal providing a similar product distribution. ${ }^{21}$

Having demonstrated the efficiency of the CFP supported FeNi alloy for the reduction of double bonds, we analyzed the hydrogenation of carbonyl groups, characterized by higher binding energy. Different biomass derivatives can afford interesting platform chemicals via carbonyl reduction. Furfural, for instance, was entirely converted at $150{ }^{\circ} \mathrm{C}$ (entry 6) giving furfuryl alcohol as the main product. Under these experimental conditions tetrahydrofurfuryl alcohol was obtained only as a minor by-product as the loss of aromaticity is energetically not favoured. ${ }^{22}$

Similarly, the attempt to reduce benzaldehyde was successful in terms of consumption of the starting material giving benzyl alcohol as a major product (entry 7).

At this point, we performed a preliminary test to prove the activity of the FeNi catalyst for the hydrogenations of crude feeds obtained from model biomass. In particular, we evaluated the reduction of crude 5-hydroxymethylfurfural (HMF), obtained via acid-catalysed dehydration of fructose in DMSO followed by extraction with ethylacetate.$^{23} \mathrm{HMF}$ is an important platform chemical used as a substitute for building blocks derived from petrochemicals. The crude HMF, containing traces of typical poisoning agents including methane sulfonic acid and DMSO, ${ }^{1}$ was dissolved in ethanol and hydrogenated under the same conditions as of furfural (entry 8 ). The conversion of the starting material was quantitative generating as the main product the useful 2,5-bis(hydroxymethyl)furan (2,5-BHF, see Fig. S5 and S6 in the ESI†), a platform chemical used for the production of polyurethane foams or polyesters. ${ }^{24}$ In order to additionally confirm that the activity of the catalysts was not compromised by the poisoning agents, the reduction of phenylacetylene was performed as described in entry 1 , immediately after the treatment of HMF and resulted unchanged. In depth analysis on the reduction of authentic hydrolyzates will be the object of future studies.

Ketones showed to be more recalcitrant towards reduction at $10 \mathrm{bar}$ of $\mathrm{H}_{2}$ and a volumetric flow of $1 \mathrm{~mL} \mathrm{~min}{ }^{-1}$. Accordingly, the reduction of cyclohexanone (entry 9) was optimized at higher $\mathrm{H}_{2}$ pressure and longer residence time and the conversion of the starting material resulted in a strong improvement (up to $84 \%$ ). In a similar way, levulinic acid, a promising biomass derived platform chemical, was completely reduced affording as the main product $\gamma$-valerolactone, a potential biofuel and renewable solvent (entry 10).

The reduction of benzonitrile (entry 11) was explored in order to study a potential poisoning of the catalyst's active sites. The reduction-condensation of benzonitrile into dibenzylamine proceeds with simultaneous generation of ammonia, which is known to poison metallic catalysts and retard 
Table 1 Conversion, selectivity and optimized temperature for the hydrogenation of different functional groups using CFP supported FeNi alloy ${ }^{a}$

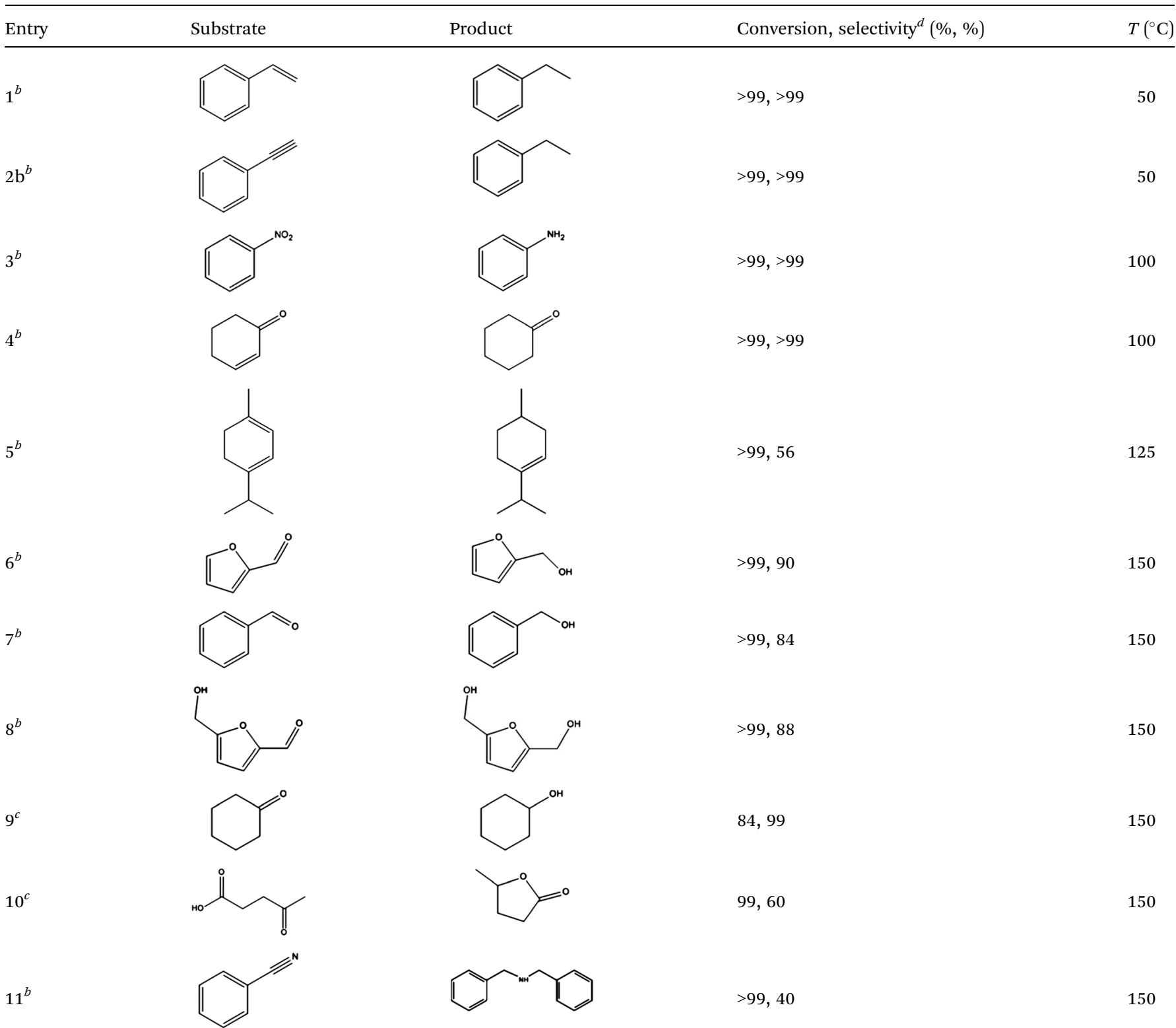

${ }^{a}$ Conditions: $0.1 \mathrm{M}$ solution of the starting material in EtOH. ${ }^{b} 1 \mathrm{~mL} \mathrm{~min}{ }^{-1}, 10$ bar $\left(\mathrm{H}_{2}\right) \cdot{ }^{c} 0.3 \mathrm{~mL} \mathrm{~min}{ }^{-1}, 50$ bar $\left(\mathrm{H}_{2}\right) .{ }^{d}$ Determined by uncorrected GC-MS analysis.

hydrogenation processes. $^{25}$ The possible deactivation of the catalyst was thus evaluated performing a three hours reduction of benzonitrile followed by benzaldehyde hydrogenation. The conversion of benzaldehyde into benzylic alcohol was only partially suppressed (a lowering of $\sim 20 \%$ ) whereas the selectivity was retained. Following a method which is normally employed for the removal of nitriles from $\mathrm{C}_{4}-\mathrm{C}_{5}$ streams of fluid catalytic cracking (FCC) units, extensive washes with water were used to restore the catalytic activity. ${ }^{26}$

Having demonstrated the generality of our catalyst for the reduction of different functional groups, we continued optimizing the reduction of two highly available and sustainable platform chemicals obtainable from lignocellulosic biomass, namely glucose and xylose. The corresponding reduced products, sorbitol and xylitol, respectively, were identified among the twelve top sugar-derived building blocks that the USDepartment of Energy depicted in their biomass report. ${ }^{27}$ Sorbitol is used in the production of vitamin $\mathrm{C}$ and as a lowcaloric sweetener. ${ }^{28,29}$ Xylitol is largely used as a functional sweetener in the food and confectionary industry as well in the health care. ${ }^{30}$ Traditionally, 'RANEY®' $\mathrm{Ni}$ is the catalyst of choice for industrial large-scale sorbitol production. Nevertheless, such a catalyst is air sensitive and susceptible to deactivation and leaches. We decided to evaluate the applicability of 
Table 2 Conversion and yield for the hydrogenation of glucose and xylose ${ }^{a}$

\begin{tabular}{|c|c|c|c|}
\hline Entry & Substrate & Product & Yield, selectivity ${ }^{b}(\%, \%)$ \\
\hline 1 & & & $>99,>99$ \\
\hline 2 & & & $>99,>99$ \\
\hline
\end{tabular}

our cellulose supported FeNi alloy for such a process. Since glucose and sugars in general are highly soluble in water but not in ethanol, their reduction constituted also a chance to evaluate the versatility of the catalyst in different solvents. Glucose and xylose were completely converted into sorbitol and xylitol by hydrogenation of the carbonyl group (Table 2, entries 1 and 2) at $150{ }^{\circ} \mathrm{C}, 50$ bar of $\mathrm{H}_{2}$ and at a flow rate of $0.3 \mathrm{~mL} \mathrm{~min}^{-1}$.

As mentioned earlier, the addition of iron to 'RANEY®' $\mathrm{Ni}$ has already been used in the past to promote and favor the activation of the $\mathrm{C}=\mathrm{O}$ bond although $\mathrm{Fe}$ showed in those catalysts to be prone to leaching, resulting in a rapid catalyst deactivation. ${ }^{13}$ For this reason, the stability of our catalyst was tested for the hydrogenation of phenylacetylene measuring conversion and selectivity as a function of time on stream. The FeNi alloy demonstrated remarkable durability as conversion remained quantitative and selectivity was mostly unchanged (up to $93 \%$ toward ethylbenzene) over a period of $80 \mathrm{~h}$ (Fig. S7 $\dagger$ ). The prolonged stability of the catalyst can be ascribed to the fact that the FeNi NPs are enwrapped and held together by the graphene layer armor.

The ease to scale-up chemical processes is an essential requirement for industrial applications. Therefore, the hydrogenation of more concentrated solutions of glucose was performed to investigate the stability of the CFP supported FeNi catalyst. The used experimental conditions were unchanged with respect to entries 1 and 2 of Table 2 . Up to a fivefold increase in the concentration of glucose, the conversion of the material was still quantitative and the yield remained higher than $90 \%$, confirming the ability of the catalysts to perform the reduction even with higher productivity. Only increasing the glucose concentration of 10 times reduced the yield to $40 \%$.

\section{Conclusions}

In conclusion we described the synthesis of a CFP supported FeNi catalyst, prepared by an inexpensive, sustainable and fast impregnation method of filter paper followed by carbothermal reduction. The resulting CFP supported bimetallic alloy displayed considerable catalytic activity for the hydrogenation of molecules with different chemical reactivity. The reduction of representative molecules obtainable from low-cost biomass sources as glucose (from cellulose), furfural and xylose (from hemicellulose) was achieved tuning the $\mathrm{H}_{2}$ pressure, the temperature and the flow rate of the liquid stream. The quantitative reduction of such molecules restituted highly commercially attractive products as sorbitol, furfuryl alcohol and xylitol, respectively. Scale-up experiments showed that the hydrogenation of glucose proceeded with excellent conversion also when the concentration was increased up to $0.5 \mathrm{M}$. Moreover, the time on stream test proved how the stability of the catalyst remained almost unchanged over 80 hours. The proposed CFP supported FeNi alloy represents therefore a viable alternative to rare metals, including $\mathrm{Pt}, \mathrm{Pd}, \mathrm{Rh}$ and $\mathrm{Ru}$ for hydrogenation processes. Future experimentations will focus on the use of this promising environmentally benign catalyst in the context of integrated biorefinery schemes for the upgrade of lignocellulosic biomass.

\section{Notes and references}

1 S. Nishimura, in Handbook of Heterogeneous Catalytic Hydrogenation for Organic Synthesis, New York, 2001.

2 J. G. de Vries and C. J. Elsevier, Handbook of Homogeneous Hydrogenation, Weinheim, 2007.

3 L. T. Peiró, G. V. Méndez and R. U. Ayres, Environ. Sci. Technol., 2013, 47, 2939-2947.

4 European Commission, Critical Raw Materials for the European Union Commission, 2010.

5 M. Buchert, D. Schueler and D. Bleher, Sustainable Technologies and Their Recycling Potential, UNEP, July 2009.

6 I. McDonald, G. C. Sloan, A. A. Zijlstra, N. Matsunaga, M. Matsuura, K. E. Kraemer, J. Bernard-Salas and A. J. Markwick, Astrophys. J., Lett., 2010, 717, L92-L97.

7 C. Rangheard, C. de Julian Fernandez, P.-H. Phua, J. Hoorn, L. Lefort and J. G. de Vries, Dalton Trans., 2010, 39, 84648471.

8 A. Welther, M. Bauer, M. Mayer and A. Jacobi von Wangelin, ChemCatChem, 2012, 4, 1088-1093.

9 R. Hudson, G. Hamasaka, T. Osako, Y. M. A. Yamada, C.-J. Li, Y. Uozumi and A. Moores, Green Chem., 2013, 15, 2141-2148.

10 D. M. Alonso, S. G. Wettstein and J. A. Dumesic, Chem. Soc. Rev., 2012, 41, 8075-8098.

11 V. Molinari, C. Giordano, M. Antonietti and D. Esposito, J. Am. Chem. Soc., 2014, 136, 1758-1761.

12 J. W. C. Liberatori, R. U. Ribeiro, D. Zanchet, F. B. Noronha and J. M. C. Bueno, Appl. Catal., A, 2007, 327, 197-204. 
13 P. Gallezot, P. J. Cerino, B. Blanc, G. Flèche and P. Fuertes, J. Catal., 1994, 146, 93-102.

14 S. Sitthisa, W. An and D. E. Resasco, J. Catal., 2011, 284, 90101.

15 Y. Chen, X. Luo, G.-H. Yue, X. Luo and D.-L. Peng, Mater. Chem. Phys., 2009, 113, 412-416.

16 S. Gurmen, B. Ebin, S. Stopić and B. Friedrich, J. Alloys Compd., 2009, 480, 529-533.

17 B. Schrick, J. L. Blough, A. D. Jones and T. E. Mallouk, Chem. Mater., 2002, 14, 5140-5147.

18 S. Glatzel, Z. Schnepp and C. Giordano, Angew. Chem., Int. Ed., 2013, 52, 2355-2358.

19 F. Schüth, Chem. Mater., 2014, 26, 423-434.

$20 \mathrm{~J}$. March and M. B. Smith, in March's advanced organic chemistry: reactions, mechanisms and structure, Wiley, Hoboken, N.J., 2007.

21 V. F. D. Álvaro and R. A. W. Johnstone, J. Mol. Catal. A: Chem., 2008, 280, 131-141.
22 T. B. L. W. Marinelli, J. H. Vleeming and V. Ponec, Stud. Surf. Sci. Catal., 1993, 75, 1211-1222.

23 B. F. M. Kuster, Starch/Staerke, 1990, 42, 314-321.

24 X. Tong, Y. Ma and Y. Li, Appl. Catal., A, 2010, 385, 1-13.

25 E. B. Maxted, Adv. Catal., 1951, 3, 129.

26 M. M. Ramírez-Corredores, Z. Hernández, J. Guerra, R. Alvarez and J. Medina, Fuel Process. Technol., 2003, 81, 143-154.

27 T. Werpy and G. Petersen, Top Value Added Chemicals from Biomass: Volume I - Results of Screening for Potential Candidates from Sugars and Synthesis Gas, 2004.

28 J. J. Bozell and G. R. Petersen, Green Chem., 2010, 12, 539554.

29 A. Corma, S. Iborra and A. Velty, Chem. Rev., 2007, 107, 24112502 .

30 L. Vernacchio, M. J. Corwin, R. M. Vezina, S. I. Pelton, H. A. Feldman, T. Coyne-Beasley and A. A. Mitchell, Pediatrics, 2014, 133, 289-295. 